\title{
Lionel Laborie, Enlightening Enthusiasm. Prophecy and Religious Experience in Early Eighteenth- Century England
}

Manchester, Manchester Univesity Press, 2015, 272 p., bibliographie. Index. Illustrations.

Régis Dericquebourg

\section{(2) OpenEdition}

\section{Journals}

Édition électronique

URL : http://journals.openedition.org/assr/28285

DOI : $10.4000 /$ assr.28285

ISSN : $1777-5825$

Éditeur

Éditions de l'EHESS

Édition imprimée

Date de publication : 31 décembre 2016

Pagination : 344

ISSN : 0335-5985

Référence électronique

Régis Dericquebourg, "Lionel Laborie, Enlightening Enthusiasm. Prophecy and Religious Experience in Early Eighteenth-Century England », Archives de sciences sociales des religions [En ligne], 176 | octobredécembre 2016, mis en ligne le 20 juillet 2017, consulté le 24 septembre 2020. URL : http:// journals.openedition.org/assr/28285; DOI : https://doi.org/10.4000/assr.28285

Ce document a été généré automatiquement le 24 septembre 2020.

(C) Archives de sciences sociales des religions 


\section{Lionel Laborie, Enlightening Enthusiasm. Prophecy and Religious Experience in Early Eighteenth- Century England}

Manchester, Manchester Univesity Press, 2015, 272 p., bibliographie. Index. Illustrations.

Régis Dericquebourg

\section{RÉFÉRENCE}

Lionel Laborie, Enlightening Enthusiasm. Prophecy and Religious Experience in Early Eighteenth-Century England, Manchester, Manchester Univesity Press, 2015, 272 p., bibliographie. Index. Illustrations.

1 Plusieurs auteurs, comme Christopher Mac Intosh (The Rose Cross and the age of Reason, Leiden, Brill, 1992), ont montré que la réalité idéologique du Siècle des Lumières n'était pas conforme à la vision unilatérale d'une époque entièrement rationaliste qui avait été celle des historiens et des philosophes. Ils ont souligné que des spiritualités diverses et une idéologie de la raison y avaient coexisté. L'auteur rappelle que les « Lumières » ont été déconstruites dans la recherche actuelle en prenant appui sur de multiples variantes : religieuses, théologiques, catholiques, juives, rosicruciennes, etc. Et s'il se défend de vouloir ajouter une nouvelle variante de la déconstruction, il se propose de présenter une nouvelle "zone d'ombre" des Lumières: celle des French Prophets auxquels il consacre ce livre.

2 Pourquoi eux ? Parce qu'ils apportent dans la seconde moitié du XvIII ${ }^{\mathrm{e}}$ siècle un réveil religieux marqué par ce que l'auteur appelle «l'enthousiasme» et qui recouvre un protestantisme marqué par des états de "possession par l'Esprit saint» et par la revendication d'une relation exclusive avec Dieu qui évince la médiation par un clergé. 
Comme les charismatiques et les pentecôtistes actuels, ils manifestaient des dons de prophétie, de vision, de guérison, de glossolalie. L'auteur nous rappelle cependant que le mot «enthusiasm » était aussi attribué aux paracelsiens et autres ésotéristes qui ne manifestaient pas de tels dons. On peut en déduire qu'il qualifie aussi une spiritualité intense et hors piste fondée sur l'expérience religieuse. Le livre est donc consacré à l'histoire de ces French Prophets qui auraient été ignorés pendant longtemps par les historiens, puisque les premières études historiques remonteraient à 1970. L'auteur se propose de réexaminer la controverse à leur propos et de les inscrire dans le panorama religieux du XvIII ${ }^{\mathrm{e}}$ siècle.

3 Les French Prophets sont issus de la persécution des protestants français après la révocation de l'Édit de Nantes (1685). Le protestantisme devenu une religion clandestine subit les assauts brutaux de la monarchie (dragonnades, villages brûlés, enfants confiés à des institutions catholiques, etc.). Dans la pratique religieuse des protestants, on assiste déjà à la manifestation de dons charismatiques. Quelques membres de l'élite de la résistance (les camisards) quittent la France pour Londres au début $\mathrm{du} \mathrm{xVIII}^{\mathrm{e}}$ siècle. Ils y rejoignent les 50000 huguenots français réfugiés en Angleterre (10 000 en Irlande). Là, ils commencent à prêcher, à manifester des dons pentecôtistes, dont celui de prophétiser, et ils créent un revival millénariste. Ils annoncent la chute de l'antéchrist, le retour du Christ et la Parousie. Londres est la nouvelle Jérusalem utopique. Ils bénéficient du Toleration Act (1685) qui garantit une liberté religieuse et ils s'inscrivent dans une veine millénariste présente depuis longtemps en Angleterre.

4 De 1706 à 1746, le groupe de trois camisards (Fage, Cavalier, Marion) passe à 665 prédicateurs qui attirent chacun une centaine de personnes à chaque assemblée. L'auteur réfute la thèse d'une marginalité de ces prédicateurs puisqu'ils sont économiquement bien intégrés et qu'ils captivent un public " socialement respectable » et "moralement irréprochable ", cela étant facilité par le niveau d'instruction élevé. Ils reçoivent un soutien financier de riches huguenots. Pour l'auteur, les French Prophets (F. P.) sont plus riches que les membres des autres dénominations, bien que les archives sur les aspects socio-économiques de leurs fidèles soient peu fournies. En tout cas, les F. P. et leur public ne sont pas semblables aux mouvements millénaristes protestataires $\mathrm{du}$ XVII ${ }^{\mathrm{e}}$ siècle anglais (Ranters, Muggletoniens, Diggers) qui étaient des pauvres (cf. Michaël Hill : Le monde à l'envers, Paris, Payot, 1977).

5 Lionel Laborie estime que la moitié des F. P. furent des femmes, bien qu'elles aient peu de visibilité dans les archives, puisqu'elles apparaissent sous les désignations de « sœur de... », « épouse de... ». Elles sont moins instruites et moins riches que leurs homologues masculins. Pour l'auteur, rien n'autorise une lecture féministe de leur conduite. D'ailleurs celles qui ont émis des propos féministes ont été exclues. Après s'être implantés à Londres et en Angleterre, en 1708, les F. P. réorganisent leur mouvement. Ils créent douze groupes de missionnaires en prenant modèle sur les douze tribus de douze mille membres oints d'Israël (selon Révélation 7:4-8) en vue d'étendre leur prosélytisme en Europe. Leur nombre reste cependant faible par rapport aux dénominations de l'époque. Toutefois, ils auraient été les plus universalistes, les plus œcuméniques et les plus transgressifs de leur temps. Après leur disparition, ils ont continué à hanter les mouvements « revivalistes » un demi-siècle plus tard.

6 Sur le plan politique, les F. P. ne furent pas " antisystème », comme l'ont été et le sont encore les millénaristes radicaux. Ils prédisent la chute de Babylone qui représente les 
systèmes politiques, mais cela reste symbolique, car ils ne font rien qui puisse hâter sa fin et ils ne se sont pas engagés dans des réformes sociales pour améliorer le sort des pauvres. Sur le plan théologique, ils rejettent la doctrine calviniste de la prédestination, ils ne pratiquent pas l'eucharistie dans les assemblées, mais en petits groupes, ils accueillent les non baptisés. L'auteur les pense influencés par des montanistes puisqu'ils admettent comme eux que la prophétie passe avant l'institution d'une hiérarchie ecclésiale. Ils sont évidemment antipapistes. Ils se revendiquent du christianisme primitif et de ses expériences de possession par l'Esprit Saint. Ils ont intéressé John Wesley qui a vu en leur expérience extatique ce qui manquait à un anglicanisme trop formaliste bien qu'il fut critique à leur égard sur d'autres plans. Les F. P. ne se sont jamais présentés comme une figure biblique. Ils ont remis au goût du jour le Livre des Révélations. Dans les assemblées, ils se contentent de jouer des saynètes bibliques. Leur activité thaumaturgique s'est accrue progressivement : ils sont devenus des sortes de "Healer-prophets", proclamant la réalité du miracle de guérison et allant jusqu'à la tentative osée de vouloir ressusciter l'un des leurs (Emes) en 1708. L'échec a entaché leur réputation.

7 Les F.P. ont beaucoup utilisé l'imprimerie pour diffuser leur message. L'imprimé permet de toucher un public plus vaste que la prédication orale et crée une communauté textuelle, et les textes figent la prédication alors que la transmission orale peut déformer le message. Mais les rassemblements subsistèrent en vertu de l'attente des protestants : « entendre la Parole biblique ». La diffusion d'imprimés a été favorisée par le Licensing Act (1695) qui accordait la liberté de la presse en Angleterre. Naturellement la diffusion de leurs écrits a permis aux détracteurs de répandre des pamphlets à leur propos sous la forme de la satire, comme l'a fait Jonathan Swift, luimême pasteur.

8 L'implantation d'un mouvement religieux ne va pas sans critiques, ni conflits. Leur succès relatif semble avoir gêné des organisations religieuses rivales. Leurs avertissements prophétiques ont parfois suscité de la colère, l'opposition aux F. P. a parfois dégénéré en violence. Les opposants anglais au traité de Douvres (1670), qui rapprochait politiquement la France et l'Angleterre, les ont considérés comme des catholiques déguisés et des comploteurs papistes (p.175). Ils ont dû affronter des procès et on leur a interdit de réunir des assemblées (Marion, Daudé, Fatio). Dans un siècle où les médecins voulaient se démarquer des charlatans, progresser dans l'étude $\mathrm{du}$ corps et du psychisme, on assiste à la médicalisation de l'expérience religieuse extatique. L'auteur consacre un chapitre intéressant au projet de développement de la médecine de l'époque en Angleterre et à la médicalisation de l'expérience religieuse des F. P. Le traitement des F. P. par leurs opposants ressemble étrangement aux arguments employés par les détracteurs des sectes à la fin du XIX ${ }^{e}$ siècle, puis dans la seconde moitié du $\mathrm{xx}^{\mathrm{e}}$ siècle et jusqu'à présent. Nous avons là la matrice des arguments de l'opposition aux groupes religieux minoritaires : de l'influence néfaste sur les enfants à la psychiatrisation de la croyance en passant par l'accusation de corruption des esprits, d'usage de drogues (ergotisme) pour avoir des visions... À l'époque, leurs opposants voulaient les soigner, mais les traitements manquaient, alors que de nos jours les opposants aux sectes utilisent la déprogrammation. Certains proposent des traitements psychotropes dont on trouve le projet au Siècle des Lumières.

9 Pour l'auteur, les F.P. ont eu bien plus d'importance qu'on ne l'a imaginé. Ils incarnaient un courant millénariste vivant dans le paysage religieux jusqu'au plus haut 
niveau de la société à l'aube du "Great Awakening». Ils ont occupé une place importante dans les débats publics du $\mathrm{xVIII}^{\mathrm{e}}$ siècle. Ils perpétuaient l'hérésiographie dans la période moderne quand les uns et les autres s'accusaient d'imposture. Ils montrent - avec d'autres phénomènes comme la parution d'écrits prophétiques, miraculeux et ésotériques $a u \mathrm{XVIII}^{\mathrm{e}}$ siècle - qu'au sein des Lumières coexistaient des expressions de «l'irrationnel » et une revendication de la Raison chez des philosophes rationalistes, qui, eux-mêmes, avaient souvent fait une expérience mystique à un moment de leur vie. Le $\mathrm{XVIII}^{\mathrm{e}}$ siècle aurait ainsi été marqué par un jeu réciproque entre la raison et la religion. 